\title{
"Vão achar que é uma piada, mas, para nós, não!": discursos de resistência em clubes brasileiros de futebol gay
}

\author{
Gustavo Henrique Carvalho de Castro ${ }^{1}$ \\ MARCUS VINICIUS SOARES SIQUEIRA ${ }^{1}$ \\ 1 Universidade de Brasília (UNB) / Programa de Pós-Graduação em Administração, Brasílıa - DF, Brasil
}

\begin{abstract}
Resumo
No futebol, a discriminação contra homossexuais é perpetrada pela injúria homofóbica, ato performativo de fala que silencia e afasta indivíduos gays do referido esporte, reforçando o culto à masculinidade hegemônica. Como reação, clubes de futebol gay têm emergido para proporcionar a participação dos homossexuais no esporte. Reconhecendo a relevância dessas iniciativas como práticas de resistência, neste artigo são analisados discursos de resistência à heteronormatividade sustentados por jogadores de clubes de futebol gay. Para tal, foram entrevistados 22 jogadores gays integrantes dos referidos clubes presentes em nove capitais brasileiras. Os relatos, interpretados sob a ótica da análise do discurso de Foucault, revelaram três discursos de resistência permeando tais iniciativas: ressignificação da injúria pelo humor; regras de interação; e silenciamentos e invisibilidades. Conclui-se que os discursos operam em uma lógica dual, produzindo enunciados que, embora tensionem a ordem gênero-sexualidade e o regime do armário, não impedem a persistência de enunciados que, paradoxalmente, atuam reforçando estes dispositivos heteronormativos.
\end{abstract}

Palavras-chave: Resistência. Heteronormatividade. Futebol gay. Discurso.

\section{“They'll think it's a joke, but for us, it is not!": speeches of resistance from Brazilian gay soccer clubs}

\begin{abstract}
In soccer, discrimination against homosexuals is perpetrated by homophobic injury, a performative speech act that silences and excludes gay individuals, reinforcing the hegemonic masculinity. As a reaction, gay soccer clubs have emerged to provide participation in the sport. Recognizing its relevance as practices of resistance, this article analyzes discourses of resistance to heteronormativity supported by players from gay soccer clubs. Interviews were conducted with 22 gay players from these clubs present in nine Brazilian capitals. According to the interviews, interpreted from the perspective of Foucault's discourse analysis, three resistance discourses permeate such initiatives: resignification of injury by humor; interaction rules; and silences and invisibility. It is concluded that the speeches operate in a dual logic, in which the presence of statements tensioning the gender-sexuality order and the closet regime does not prevent the persistence of statements that reinforces these same heteronormative deployments.
\end{abstract}

Keywords: Resistance. Heteronormativity. Gay Soccer Clubs. Discourse.

“Pensarán que es una broma, pero no para nosotros!”: discursos de resistencia de los clubes brasileños de fútbol gay

\section{Resumen}

En el fútbol, la discriminación contra los homosexuales es perpetrada por ofensas homofóbicas, actos de habla performativos que los silencian y alejan de dicho deportes, lo que refuerza el culto a la masculinidad hegemónica. Como reacción, han surgido clubes de fútbol gay para propiciar la participación de los homosexuales. Reconociendo la relevancia de estas iniciativas como prácticas de resistencia, este artículo analiza los discursos de resistencia a la heteronormatividad apoyados por jugadores de clubes de fútbol gay. Con este fin, se entrevistaron a 22 jugadores homosexuales de estos clubes, presentes en nueve capitales brasileñas. Los relatos, interpretados desde la perspectiva del análisis del discurso de Foucault, revelan tres discursos de resistencia que impregnan tales iniciativas: resignificación de la ofensa a través del humor; reglas de interacción; y silenciamientos e invisibilidades. Se concluye que los discursos operan en una lógica dual, en la que la presencia de declaraciones que tensionan el orden de género-sexualidad y el régimen del armario no impiden la persistencia de enunciados que, paradójicamente, refuerzan los dispositivos heteronormativos.

Palabras clave: Resistencia. Heteronormatividad. Fútbol gay. Discurso. 


\section{INTRODUÇÃO}

Das sociedades ocidentais modernas à contemporaneidade, a homossexualidade tem sido considerada uma espécie de anormalidade, e o homossexual, consequentemente, estigmatizado e subalternizado frente ao ideário de masculinidade (KIMMEL, 1998; HEREK, 2004; CONNELL, 2005), que preza pela heterossexualidade compulsória como requisito para a inteligibilidade (BUTLER, 2003). Neste processo, certos discursos exercem domínio significativo, uma vez que excluem e incitam à exclusão daqueles não conformes às expectativas de normalidade, regulando e agenciando suas subjetividades (FOUCAULT, 1988).

No âmbito do futebol, homossexuais são discriminados pelo emprego de injúrias homofóbicas, atos performativos de fala que proporcionam insultos aos atletas e torcedores gays e os silenciam, reforçando o culto à masculinidade hegemônica (BANDEIRA e SEFFNER, 2013). No rol destas práticas discursivas, naturalizadas em competições e nos meios virtuais, são corriqueiros: cânticos homofóbicos; xingamentos aludindo à feminilização dos adversários; piadas pejorativas e/ou de duplo sentido; e ofensas dirigidas aos jogadores, seja por suas performances consideradas insuficientemente masculinas ou por intolerância a falhas no jogo (BANDEIRA, 2010; KIAN, CLAVIO, VICENT et al., 2011; ALMEIDA e SOARES, 2012; BANDEIRA e SEFFNER, 2013; MAGRATH, 2018).

E ainda que se manifestem discursos em prol da inclusão gay no esporte (KIAN, CLAVIO, VICENT et al., 2011; LUISI, LUISI e GEANA, 2016; CLELAND, MAGRATH e RIAN, 2018), a tônica ainda é a da tolerância, em que a inclusão preza por expectativas de conformidade, tais como elevado desempenho atlético, regulação de performances femininas e manutenção da sexualidade em segredo, desde a esfera pública à própria interação com a equipe (ANDERSON, 2009). Destarte, pelo discurso homofóbico opera-se uma opressão sistemática: trata-se de um dispositivo que emprega não apenas meios explícitos de linguagem, como também meios sutis para excluir, conformando atletas e torcedores gays ao armário (CAMARGO, 2018; SILVA JÚNIOR, 2018).

Em reação às exclusões apresentadas, clubes de futebol gay têm emergido como alternativa àqueles não alinhados aos preceitos heteronormativos. Tratam-se de equipes majoritariamente compostas por gays buscando inclusão no futebol, assim como experiências coletivas de pertencimento à comunidade gay, em detrimento das frequentes hostilidades (JONES e MCCARTHY, 2010; STASI e EVANS, 2013; BURY, 2015; JARVIS, 2015; WILLIS, 2015). Caracterizam-se, portanto, no âmbito futebolístico, como uma forma de resistência à heteronormatividade imposta socialmente.

Todavia, a literatura concernente ao fenômeno é acentuadamente exígua e concentra-se no Reino Unido, Irlanda e Islândia (JONES e MCCARTHY; 2010; STASI e EVANS, 2013; BURY, 2015; JARVIS, 2015; WILLIS, 2015), desvelando a necessidade de estudos em âmbito brasileiro, já que iniciativas similares despontaram em solo nacional, sobretudo desde 2017 (JESUS, 2019). Ademais, entende-se o surgimento de clubes de futebol gay no país como frutifera reflexão para estudos organizacionais críticos, nos termos da relação entre discurso e resistência e, particularmente, nas instituições esportivas. Uma vez que o discurso simboliza um campo de possibilidades para formas de resistência gay (FOUCAULT, 1998), a própria injúria carrega a ambivalência de também ser a propulsora da coletividade para grupos estigmatizados e marginalizados socialmente, gestando muitos movimentos gays, até mesmo no esporte (ERIBON, 2008).

O objetivo do artigo foi o de analisar discursos de resistência à heteronormatividade sustentados por jogadores de clubes brasileiros de futebol gay. Para tal, foram entrevistados 22 jogadores gays participantes de clubes oriundos de nove capitais brasileiras. Os dados foram interpretados segundo a análise de discurso de Michel Foucault, que versa sobre dispositivos discursivos, sexualidade e resistência.

A reflexão apoia-se no pressuposto da performatividade dos enunciados (BUTLER, 2003), cujos efeitos podem ser tensionados, na medida em que promovem deslizamentos em discursos ofensivos estabelecidos, seja invertendo o que eles significam, seja procedendo de acordo com eles (BUTLER, 1997; ERIBON, 2008). Assim, a pesquisa aproxima-se da epistemologia queer - vertente pós-estruturalista cujo nome diz respeito propositalmente a uma injúria, que, ressignificada, é perspectiva de engajamento frente às práticas opressivas do sistema sexo-gênero-sexualidade (SOUZA, 2017). A relevância do presente estudo está na abordagem crítica da heteronormatividade e no empenho epistemológico de compreensão das práticas de resistência frente à masculinidade hegemônica (CONNELL, 2005). Inobstante, pontua-se a característica multiforme dos estudos queer, cujas premissas são decididamente cunhadas sob a diferença epistemológica (MISKOLCI, 2012; SOUZA, 2017). 
No âmbito de estudos organizacionais críticos, o artigo sublinha o crescente interesse do campo pelas reflexões advindas dos estudos queer (SOUZA, 2017). A contribuição está em compreender que clubes de futebol gay, na condição de organizações desportivas, operam segundo a lógica do organizing, cujas unidades organizacionais não são estáveis - existindo a priori ou pré-discursivamente -, mas processos contínuos marcadamente político-discursivos (SOUZA, COSTA e PEREIRA, 2015).

\section{HETERONORMATIVIDADE E RESISTÊNCIA NOS ESPORTES}

A homofobia pode ser dimensionada em termos cognitivos, afetivos e comportamentais (HEREK, 2004; BORRILLO, 2010; PIEDRA, 2015). Na dimensão cognitiva, "[...] o objeto da rejeição não é o homossexual, enquanto indivíduo, mas a homossexualidade como fenômeno psicológico e social" (BORRILLO, 2010, p. 22). Na dimensão afetiva, faz-se alusão à "rejeição dos homossexuais" (BORRILLO, 2010, p. 22), manifesta por sentimentos de rechaço. A dimensão comportamental exemplifica-se nas interações em competições esportivas, como externalizações de ódio, agressões verbais e/ou físicas, bem como por discriminações veladas, como o ostracismo cotidiano em relação aos gays (PIEDRA, 2015).

No universo da masculinidade hegemônica, a narrativa "ser homem heterossexual" impõe-se como única possibilidade de masculinidade (CONNELL, 2005), desvelando a homofobia como um mix de sexismo e machismo. Para os homens, não ser suficientemente masculino é o primado lógico da associação entre homofobia e o padrão heteronormativo de masculinidade: medo de ser feminino, de não corresponder às expectativas culturais, de ser gay (KIMMEL, 1998). A homofobia está inscrita numa ordem social de sexualidade-gênero, cujo dualismo estruturante homo-heterossexualidade (SEDGWICK, 1993) opera como dispositivo perpetuador da heterossexualidade compulsória (BUTLER, 2003).

A heteronormatividade, portanto, é o que melhor representa efeitos dos dispositivos de sexualidade (FOUCAULT, 1988), articulando dito e não dito e impondo esquemas de produção e inteligibilidade aos sujeitos (MISKOLCl, 2012). Ela "[...] descreve a tendência do sistema sexo-gênero ocidental contemporâneo de enxergar as relações heterossexuais como a norma, e todas as outras formas de comportamento sexual como desvios dessa norma" (SPARGO, 2017, p. 53). No entanto, a linha conceitual entre homofobia e heteronormatividade é tênue, já que ambas se articulam em torno de crenças, atos e representações coletivas (BORRILLO, 2010). Assim, didaticamente, distingue-se homofobia como discriminação (reflexo) e heteronormatividade como dispositivo (produtora de inteligibilidades) (MISKOLCl, 2012).

A heteronormatividade é algo que se insere cedo nas relações esportivas. A socialização masculina no esporte inicia-se nos contextos da educação física, ambientes nos quais muitos garotos, no processo de "tornarem-se homens", assimilam códigos de gênero e recorrem a termos pejorativos entre si (LOURO, 2003; ANDERSON, 2009; BANDEIRA, 2010), promulgando, pela repetição, as performances de gênero admitidas (BUTLER, 2003). Logo, ser afeminado, por exemplo, é transgredir expectativas, pois qualquer alusão à homossexualidade configura-se ameaçadora, independentemente de o indivíduo ser gay (KIMMEL, 1998; BORRILLO, 2010).

Nesses contextos, o homossexual é associado a performance não masculina. É por via da injúria homofóbica que são reforçados, na linguagem, estigmas acerca do gay (ERIBON, 2008). Tal injúria é ato (ou série de atos) de fala, constitutivo(s) da experiência homossexual e que impõe $(\mathrm{m})$ ao gay o ultraje da própria subjetividade, produzindo como consequência a internalização da homofobia (HEREK, 2004). Em outras palavras, trata-se de insultos que inauguram discursivamente relações de domínio às quais os homossexuais estão subordinados, englobando ainda meios menos explícitos, como "[...] a fofoca, a alusão, a insinuação, as palavras maldosas, [...] o boato, [...] a brincadeira mais ou menos explícita, mais ou menos venenosa" (ERIBON, 2008, p. 64). É a injunção afetivo-cognitiva da homofobia na linguagem (BORRILLO, 2010). Pela injúria, na infância, aprende-se sobre a própria sexualidade e a dos outros (MISKOLCl, 2012).

No âmbito do futebol - esporte notadamente masculino na maioria dos países e de larga popularidade (OLIVEN e DAMO, 2001) -, a injúria homofóbica naturaliza-se sob o manto da linguagem compartilhada pelos adeptos. Para muitos deles, proferir insultos homofóbicos é algo considerado inofensivo, um autêntico meio para expressão coletiva (BANDEIRA, 2010; CLELAND, 2018). Nesse quadro, a injúria prolifera-se ao sabor da leniência de técnicos, clubes e federações, dentre outras instituições relativas ao futebol, e a homofobia confunde-se com o próprio rito interacional, balizando o jogo e sendo compreendida como socialização masculina em estádios e outros espaços (ALMEIDA e SOARES, 2012; CASHMORE e CLELAND, 2012; MAGRATH, 2018). 
Diante disso, a homossocialidade masculina (SEDGWICK, 1985) emerge nas modalidades atléticas grupais como laço social estabelecido no paradoxo de reprimir desejos homoeróticos, projetando constantemente o homossexual nos discursos, cânticos, em piadas, obscenidades e palavrões (ERIBON, 2008; CAUDWELL, 2011). A injúria e a homossocialidade corroboram o dispositivo heteronormativo, por preconizarem que o símbolo da masculinidade é ser alguém masculino, competitivo, agressivo, viril e, sobretudo, heterossexual (BANDEIRA e SEFFNER, 2013). Também, como dispositivo, possuem ação pedagógica (LOURO, 2003), já que permitem disciplinar códigos que afirmam quem é apto ao jogo e à torcida, e quem não o é (BANDEIRA, 2010; BANDEIRA e SEFFNER, 2013).

Os homossexuais, sob a constante ameaça de depreciação individual, dificilmente permanecem neste tipo de regime (ERIBON, 2008; ALMEIDA e SOARES, 2012). Assim, para participar do futebol, esquemas são adotados: como torcedores, utilizam-se de táticas para frequentar os estádios, como silenciar-se perante investidas homofóbicas ou então proferir as mesmas injúrias contra outros, mimetizando comportamentos heterossexistas (SILVA JÚNIOR, 2018); como jogadores não assumidos, ocultando a orientação sexual, segredam a vida particular no simulacro da heterossexualidade (ANDERSON, 2009); e, dos poucos que "saem do armário", isso ocorre somente após concluírem sua atuação no futebol (CLELAND, MAGRATH e RIAN, 2018). No caso de jogadores famosos, por exemplo, o coming-out, além de condená-los ao isolamento, ao ostracismo e à renegação da própria identidade, esbarra no receio de as organizações esportivas terem suas imagens comprometidas (KIAN, CLAVIO, VICENT et al., 2011; CLELAND, 2018; LUISI, LUISI e GEANA, 2016).

Desse modo, são delineados os contornos do armário no futebol, em que até é possível ser gay, desde que não se fale sobre isso (SEDGWICK, 1993). No meio esportivo, essa filosofia de segredo é conhecida como "don't ask, don't tell" (CAMARGO, 2018) - que significa "não pergunte, não conte": um mantra originado nas instituições militares em sua política de sigilo sobre práticas homo e bissexuais (BUTLER, 1997). Segundo Eribon (2008), o esporte é o lugar da identidade homossexual aberta irrealizável, pois atletas e torcedores gays são levados a entender a sexualidade como indiscutível, apesar de a própria heterossexualidade constituir-se como compulsória, transbordando em diferentes enunciações discursivas (ANDERSON, 2002; ERIBON, 2008).

Ademais, a despeito de a literatura cumular significativamente discursos de outros atores em prol da aceitação gay no universo do futebol (ANDERSON, 2002, 2005, 2009; KIAN, CLAVIO, VICENT et al., 2011; PEREIRA, ALFAIA, SOUZA et al., 2014), a tônica revestida nestes discursos - acessados majoritariamente em mídias e fóruns - é a da expressiva tolerância ao homossexual, em vez de sua plena inclusão (CAMARGO, 2018). Isso reforça o dispositivo heteronormativo diante de expectativas como: elevado desempenho atlético de gays assumidos; regulação de performances femininas; e manutenção da sexualidade no domínio do segredo, desde a esfera pública às interações com o time (ANDERSON, 2009). Assim, o problema que se coloca é que, em tais pesquisas, além de se capturar o olhar heterossexual, em lugar de cotejar relatos de esportistas gays, termina-se reificando o homossexual como desviante.

Considera-se que a discriminação homofóbica no esporte é algo sistemático, que parte de múltiplos meios de exercício do dispositivo heteronormativo, evidenciado no reforço do par gênero-sexualidade e na indução ao armário (SEDGWICK, 1993; BUTLER, 2003). Porém, para cada forma de opressão, existe a possibilidade da resistência (FOUCAULT, 1988, 1998); desse modo, a ideia de futebol especificamente gay pode sugerir discursos e práticas que representam pontos de agência para jogadores homossexuais.

Se a declaração coletiva da homossexualidade for refletida como possibilidade de tensionamento do regime do armário no esporte e da ordem sexo-gênero, perfaz-se então prática de resistência ao dispositivo de sexualidade (FOUCAULT, 1988). Nesse sentido, dispositivo não equivale a poder, como se pensa convencionalmente em dinâmica macropolítica (FOUCAULT, 1998), mas à rede instável de micropráticas, que conjuga dito e não dito e se predestina a ser uma verdade sobre o sexo, interditando determinadas formas de existência na vida pública e produzindo subjetividades (SOUZA, COSTA e LOPES, 2019). A homossexualidade é um caso da produção de corpos marginais por tal dispositivo. Em tal sistema de pensamento, a repressão sexual é também contestada, dado que o controle é imposto na forma de surtos discursivos sucessivos sobre sexualidade em múltiplos saberes (FOUCAULT, 1988), e o futebol seria um deles (BANDEIRA, 2010).

Assim, resistência é ato de transposição das condições de sujeição em persistentes tentativas de escapar à serialização de subjetividades, emancipando sujeitos como indivíduos (SOUZA, COSTA e LOPES, 2019). Como há capilaridade social do poder, a resistência nunca está no extremo da exterioridade em relação a ele, pois o poder pune exatamente por se tratar de medida de combate à resistência (FOUCAULT, 1998). 
Nesta correlação de forças, os discursos sobre gênero-sexualidade no futebol são performativos, no sentido de que (re)citam os comportamentos de gênero e sexualidade socialmente pactuados (BUTLER, 2003); alguns deles possuem status de dominância, controlando e distribuindo enunciados conforme procedimentos que asseguram os acontecimentos (FOUCAULT, 1999). Logo, a resistência pode estar no (contra)discurso, que visa reverter o poder, manifestando-se como ressignificação de discurso e, portanto, de poder, sem que deixe de "[...] ser o mesmo discurso, que procede de acordo com as mesmas categorias, mas que inverte ou transforma o que elas significam" (ERIBON, 2008, p. 378).

Considerando-se que clubes de futebol gay têm se propagado na arena internacional, cumpre reforçar que o registro teóricoempírico é escasso. No Reino Unido, por exemplo, investigou-se criticamente a não performatividade (não efetividade) dos discursos de planos de combate à homofobia no futebol por vias do fortalecimento de clubes e ligas de futebol gay, além das representações hegemônicas do masculino e a gradativa inclusão de atletas heterossexuais nestes clubes (JONES e MCCARTHY, 2010; BURY, 2015; JARVIS, 2015). Já no contexto irlandês, pesquisou-se como jogadores gays inseridos em clubes e ligas gays promovem práticas disruptivas, ao passo que também reforçam determinadas normas de gênero e sexualidade (WILLIS, 2015). Na Islândia, por sua vez, observou-se a incorporação do gênero nos discursos dos jogadores gays (STASI e EVANS, 2013). Por fim, a literatura incentiva análises de outras formações gays no futebol, ao redor do globo, correspondendo ao presente trabalho de reflexão sobre o discurso de resistência à heteronormatividade no futebol gay no Brasil.

\section{PROCEDIMENTO METODOLÓGICO}

Esta pesquisa foi desenvolvida com a participação de jogadores de clubes amadores de futebol gay brasileiros, os quais, em sua maioria, faziam parte da Liga Nacional de Futebol Gay (LGNF) em 2019. Em breve caracterização, a LGNF, doravante LiGay, é uma federação criada em 2017 para disseminar eventos associados ao futebol gay no país. Desde então, realiza semestralmente uma edição da Champions Ligay, campeonato cuja marca é ser uma paródia do campeonato europeu Champions League ${ }^{\circledR}$, unindo festa e futebol (JESUS, 2019).

No primeiro semestre de 2019, em Brasília, foi realizada a quarta edição do evento, contando com 24 equipes, uma local e as outras provenientes de diversas capitais brasileiras. No contexto desse evento, foram selecionados por conveniência e entrevistados, em dois dias, 17 jogadores gays provenientes de oito times das cidades de Manaus, Goiânia, Belo Horizonte, Vitória, São Paulo, Rio de Janeiro, Porto Alegre e Curitiba. Posteriormente, por meio da técnica de seleção bola de neve (snowball sampling), foram entrevistados mais cinco jogadores de dois clubes de futebol gay do Distrito Federal, sendo um não federado à LGNF. O número total de jogadores entrevistados foi de 22.

Para a condução das entrevistas, adotou-se o roteiro semiestruturado, suportado tanto em aprovação prévia por comitê de ética de pesquisa, como pela autorização escrita de cada participante, tanto para ser voluntário quanto para a transcrição do áudio da entrevista tendo como fim a pesquisa. O roteiro adotado possibilitou apreender visões e vivências dos jogadores acerca de homofobia e heteronormatividade no futebol e na vida em sociedade, bem como acerca das práticas de resistência exercidas no futebol gay.

Em relação ao perfil dos entrevistados, todos afirmaram-se gays; a maior parcela é oriunda de times localizados em Brasília, Rio de Janeiro e São Paulo; possui formação superior, sendo recorrente ocupações como educador físico, servidor público e jornalista; e idade média aproximada de 29 anos. Cada interlocutor encontra-se identificado nos excertos por meio de código que vai de J1 a J22, de modo a não comprometer o sigilo de suas identidades.

Uma primeira observação geral dos relatos permitiu colher os enunciados mais recorrentes e significativos para o objetivo do trabalho, os quais foram organizados dentro de um corpus textual. Para Foucault (2008), além da repetição como princípio para reconhecer o enunciado como tal, é preciso não restringi-lo a ato de fala, frase ou proposição, mesmo porque ele é conjunto de signos que, já precedido de uma teia de discursos e saberes, possibilita, ainda que por aleatoriedade, reafirmar determinadas formações discursivas. Estas, por sua vez, são identificadas caso seja possível "[...] mostrar como todas derivam (malgrado sua diversidade por vezes extrema, malgrado sua dispersão no tempo) de um mesmo jogo de relações" (FOUCAULT, 2008, p. 76). Assim, depreende-se que, ao passo que enunciado e formação discursiva encontram-se intrinsecamente relacionados, discurso é, no domínio foucaultiano, um dito que repousa em outro precedente (FOUCAULT, 2008). 
Assim, a análise efetuada recorreu às dimensões de delineamento externos dos discursos, os quais, apesar de não consistirem, em sentido lato, em categorias teóricas, possibilitaram apreender as regras que "[...] se exercem de certo modo do exterior; funcionam como sistemas de exclusão; concernem, sem dúvida, a parte do discurso que põe em jogo o poder e o desejo" (FOUCAULT, 1999, p. 21), a saber:

- Interdição da palavra (em quais circunstâncias o discurso sobre a sexualidade é interditado? Quem pode e quem não pode falar? O que não pode ser falado?);

- Separação e rejeição (quais os silêncios responsáveis pela separação e rejeição dos discursos? O que é censurado? Que discurso é tido como nulo ou irracional?);

- Vontade de verdade (quais práticas de saber engendram a verdade sobre o objeto em questão? Quais instituições se encarregam de disseminar saberes no objeto estudado?).

A crítica presente baseia-se nas reflexões foucaultianas a respeito do dispositivo de sexualidade e da resistência (FOUCAULT, 1988, 1998), alinhando-se ao empreendimento intelectual da crítica genealógica (FOUCAULT, 1999), na qual, além da noção de formação discursiva, os discursos, como o da sexualidade, passam a ser compreendidos enquanto situados no campo das relações de força.

Como uma análise queer, por fim, intenta-se apreender a ordem sexo-gênero e o regime do armário, bem como o tensionamento (ou reforço) destes dispositivos em enunciados sobre: inteligibilidade, injúria, citacionalidade, performatividade do gênero-sexo, interpelação, masculinidade hegemônica e homossocialidade, dentre outros conceitos outrora abordados.

\section{RESULTADOS E DISCUSSÕES}

Para Foucault (1998), os indivíduos tornam-se, continuamente, sujeitos por meio de processos de subjetivação. No campo esportivo, a masculinidade hegemônica pode ser considerada como assujeitamento, legitimando a reprodução de valores superiores para o masculino e heterossexual e de esquemas depreciativos sobre a homossexualidade (ANDERSON, 2005; CONNELL, 2005).

Em (J4), são sugeridos indícios sobre como o futebol convencional engendra determinados mecanismos de sujeição:

Olha, eu jogo futebol desde quando eu me entendo por gente. Então, eu sempre joguei futebol, mas nunca podendo ser eu mesmo, né? O [menciona próprio nome], que é gay, nunca podendo me assumir. Então sempre nas peladas, nos jogos, eu ouvia papo de mulheres e tal e eu nunca podia chegar e falar de um namorado ou de alguma situação dentro do meio gay, que é o meu meio, né? Então eu não era eu mesmo (J4).

O discurso sobre a experiência de se fazer jogador de futebol, para atletas gays, passa pela interdição (FOUCAULT, 1999) do atributo homossexualidade (FOUCAULT, 1988), que, no caso de (J4) implica renúncia a um marcador central de vida, correspondente a deixar de ser ele mesmo em jogos, lugares, por excelência, da hegemonia masculina (BANDEIRA e SEFFNER, 2013).

Segundo Louro (2003, p. 75), em sociedades como a brasileira, “[...] gostar de futebol é considerado quase uma 'obrigação' para qualquer garoto 'normal'”. Assim, entende-se o gay como alguém subjetivado no futebol pela impossibilidade de viver a experiência da própria orientação sexual, de maneira livre e descompromissada com julgamentos, o que interfere na própria concepção de agência do indivíduo - exercício do desejo, em contraponto à ordem imposta (MISKOLCI, 2012). 0 enunciado é representativo do armário esportivo (CAMARGO, 2018), em que mesmo o coming-out é algo não unívoco, de modo que o indivíduo, em vários momentos, retrocede para o armário (SEDGWICK, 1993).

(J8) retrata, metaforicamente, esse processo: “[...] a gente fica dentro de um casulo porque você não pode... primeiro porque você não pode demonstrar que você é gay, né? Então você tem, mesmo que velado, um monte de regras assim, tipo...você tem que sair com mulher, você tem que...você não pode ter certos tipos de comportamento dentro daquele meio" (J8). Assim, manter a identidade legítima perante os pares, no contexto do futebol, é empreender táticas que, na medida em que protegem, atendem aos anseios heteronormativos. Ressaltando-se que muitos torcedores gays usam a imitação como forma 
de proteção em meio às torcidas organizadas em estádios brasileiros (SILVA JÚNIOR, 2018). É a performatividade do gênero em ação, a habilidade existente nos enunciados de indicar os signos que citam (e incitam a) o masculino-heterossexual: "sair com mulher", "não ter certos comportamentos..." Um alinhamento que não só reflete expectativas heterossexistas, mas as reitera em moldes quase compulsórios (BUTLER, 2003).

No que concerne às discriminações vivenciadas nas instituições esportivas por quem jogara anteriormente em times "héteros" (forma como muitos dos entrevistados se referiram aos times convencionais), (J15) refletiu sobre como sua orientação sexual foi objeto de rechaço: "[eles] evitaram, evitaram contato, mas, normal, né? Vai levando a vida normal. Só que eles ficaram surpresos, né? Não pela ideia de não saber que eu era homossexual, mas que eu gostava do esporte [risadas]" (J15). $\mathrm{O}$ enunciado carrega o pressuposto de que homossexualidade e futebol seriam antagônicos. No Brasil, o esporte forja corpos masculinos produtivos até mesmo no lazer (MISKOLCl, 2013), de modo que o corpo homossexual é visto como improdutivo e, portanto, excluído do esporte. (J18) corrobora: "[...] a sociedade vê um cara jogando bola, é homem né? [...] Você não vai encontrar ali um - desculpe a palavra aqui -, um 'viadinho"” (J18).

Assim, as relações entre os próprios homens são controladas e objetos de saberes, pedagogias e formações discursivas (FOUCAULT, 1988), ordens perante as quais os interlocutores tornam-se alvos de interpelação (BUTLER, 2003). O preconceito no esporte tem marcadores da discriminação velada, que não se qualifica nem como agressão verbal, nem portadora da máscara do bom humor (PIEDRA, 2015). É o preconceito inscrito no silêncio, na ausência de fala, mas, nem por isso, dissociado do discurso (FOUCAULT, 1999).

Os enunciados abordados corroboram o silêncio das instituições esportivas: "locker room culture" (cultura de vestiário) (CAMARGO, 2018). É a interdição discursiva, que ganha os seus contornos nas exclusões cotidianas e no aceite do estigmatizado, perpetrada por agências e clubes, mídia e imprensa, fãs (KIAN, CLAVIO, VICENT et al., 2011; CASHMORE e CLELAND, 2012; CLELAND, 2018; MAGRATH, 2018) e até mesmo por sistemas legalmente instituídos (ALMEIDA e SOARES, 2012; BANDEIRA e SEFFNER, 2013).

Dessa forma, se o silêncio é estratégia discursiva que admite certos discursos, às custas da exclusão de outros, e se o que coloca risco à homossocialidade masculina não é o ato erótico em si, mas a fala sobre ser gay, como podemos caracterizar as práticas discursivas de resistência sustentadas pelos clubes brasileiros de futebol gay em torno da masculinidade hegemônica, que impera como ordem discursiva de gênero e sexualidade? Embasados na interpretação dos relatos, apresentamos e discutimos, em subseções, três discursos de resistência identificados.

\section{Ressignificação da injúria pelo humor}

Segundo Foucault (1999), um discurso não possui sentido definido para sempre, de modo que ele age conforme as funções estratégicas de que se ocupa. Nesse sentido, jogadores gays de futebol são encarados como provisórios, citando regras de gênero e sexualidade, dentro de uma matriz que comunica a quais sujeitos se confere inteligibilidade.

Pesquisas sobre futebol gay, em âmbito internacional, indicaram que a experiência de fazer parte de clubes especificamente gays proporciona inclusão, ao promover práticas coletivas que favorecem o espírito de jogo genuíno e evitam excessos de hostilidades e agressões (JONES e MCCARTHY, 2010; STASI e EVANS, 2013; WILLIS, 2015). Acerca dos "esportes LGBT", Camargo e Rial (2011), em vivências nessas competições, indicaram que a ironia é uma figura de linguagem constantemente empregada pelos atores. Expressões de chamamento no feminino, por exemplo, são parte do rito de interação entre homens esportistas gays, o que já fora compreendido inclusive nos estudos sobre coletividades gays (ERIBON, 2008).

Esse discurso bem-humorado foi levado para o âmbito das torcidas queer no Brasil, que eclodiram no ano de 2013 como manifestações de resistência, especialmente, no contexto virtual e em alguns estádios, congregando reivindicações de respeito por torcedores assumidamente gays (BANDEIRA e SEFFNER, 2013). Assim, a ironia é uma figura de linguagem observada também nos times investigados, visibilizada em enunciados que compreendem, para contestar a heteronormatividade, o arquétipo bicho-humor-erotismo, notadamente em nomes como, por exemplo, "Alligaytors", "BallCats", "BeesCats SoccerBoys" e "Predadores".

A marca bem-humorada do futebol gay tem sua genealogia na própria nomenclatura que os times adotam (JESUS, 2019). Em sua maioria, sugerem, por exemplo, afronta, bravura e diversidade como princípios de resistência gay, mas também erotismo e ironia. (J10) indica que o humor e a piada são meios de afirmar a própria orientação sexual, e enuncia: "Ah, é afirmação! 
É se afirmar. Beleza, você me chama de viado? Eu sou viado mesmo! Vai fazer o quê? [tom de risada]. Vai me excluir por causa? [risadas]" (J10). Ou como coloca (J20), "Olha, quer chamar a gente de 'viado'? A gente é mesmo. A gente é muito mais". Já (J12) salienta a simbologia por detrás dos nomes dos clubes, atribuindo-lhe um significado de sobrevivência: "É uma marca de sobrevivência. É um modo de nos mantermos vivos, presentes. Não dá para ir na força? vamos no humor. [...] Para mostrar que resistimos por meio da graça" (J12). Assim, vocábulos como "afirmação" e "sobrevivência", extraídos das próprias explanações sugerem a emergência de formas de (re)organização da subjetividade nestes movimentos (SOUZA, COSTA e PEREIRA, 2015).

Eu acho que é da natureza do gay ele ser mais folclórico, ele gostar de dançar... [...] Ele é mais expansivo por natureza. Acho que isso traz felicidade. Então, quando chega aqui... todo mundo tem uma semana difícil, trabalha muito. É um momento de lazer, então, "BLUFT!" Explode. Você explode purpurina para tudo que é lado, porque aqui é o momento de extravasar. [...] Quando você faz um gol decisivo no futebol hétero, você provoca meio que um afronte. No gay, quando ele faz alguma jogada que ele arrasa muito, ele imita Beyonce, ele dá alguns gritinhos, normal do meio gay assim [...] Tipo, num futebol hétero seria inadmissível um cara fazer um gol e sair rebolando, comemorando. Fica parecendo que é um deboche enorme (J19).

(J19) sugere a inserção do humor nas partidas em momentos de maior vibração do time, indicando séries de resistências que se valem não somente da ressignificação de injúrias, mas ainda de atos corporais (BUTLER, 2003), sugerindo irreverência. A felicidade é elemento da elaboração discursiva sobre o que é ser gay, que lhe permite adotar práticas corporais dissonantes do heteronormativo (CAMARGO, 2016), como "dançar", "imitar a Beyonce" e "sair rebolando, comemorando"; enquanto também irrompe com a ordem discursiva, operando novas práticas discursivas, seja dando "alguns gritinhos", seja proferindo "piadas" do "meio gay", ou mesmo ressignificando a própria injúria homofóbica sofrida.

Nesse sentido, pela apropriação das palavras depreciativas ressignifica-se a própria injúria (BUTLER, 1997; ERIBON, 2008), e isso se reflete de maneira intensiva nos times pesquisados. Como pontua (J7), "[...] num primeiro momento é uma questão até de chamar a atenção e mostrar que a gente não precisa colocar o nome heteronormativo no nome do time para ser um time de futebol. É mostrar que realmente usando um time que as outras pessoas, os héteros, ou outras pessoas, vão achar que é uma piada, mas, para nós, não! É um motivo de orgulho" (J7). Assim, a visibilidade é promovida com mensagem que tem propósito de "chamar a atenção", pois, ainda que inicialmente aparente ser uma brincadeira (ou injúria), é um meio de transmitir orgulho e sentimento de coletividade aos participantes.

Tal enunciado se alinha com o que outro jogador, categoricamente, pontuou: "é afirmação" (J10). Depreende-se que "colocar o nome heteronormativo", nestas circunstâncias, é enfraquecer a estratégia discursiva de resistência empregada. Ou seja, "[...] não se deve imaginar um mundo do discurso dividido entre o discurso admitido e o discurso excluído, ou entre o discurso dominante e o dominado; [...] uma multiplicidade de elementos discursivos que podem entrar em estratégias diferentes" (FOUCAULT, 1988, p. 94). Tampouco que discursos reversos conduzem a se falar necessariamente de outro discurso pois podem remeter àquele mesmo discurso, que, agora, procedendo em conformidade com as mesmas categorias, inverte o primeiro discurso ou transforma o que tais categorias significam (BUTLER, 1997; ERIBON, 2008).

\section{Regras para interação}

Outro discurso é o das regras do jogo de futebol gay. Uma delas relaciona-se às próprias ofensas e condutas que envolvem expressões pejorativas. (J12), quando perguntado sobre como a mudança se dá por meio da ressignificação discursiva, apresenta-a ao tratar do futebol gay: “É claro que entre amigos um chama o outro de gay, de bicha, de viado. São brincadeiras. A gente sabe o tom. Mas, não é permitido; é, aliás, absolutamente proibido, ofensas, homofobia ou qualquer outro tipo de agressão. Atletas assim, times que vêm com essa consciência, são filtrados e, se não se adequam, são excluídos" (J12).

Esta enunciação efetiva um mecanismo de regulação da injúria, uma vez que, dependendo da conotação que ela carrega, pode retroceder ao próprio problema que a origina: o preconceito homofóbico. Esta inferência encontra suporte em "a gente sabe o tom": trata-se de um meio de recuperar a zona de inflexão que enseja o insulto homofóbico. Tal mecanismo implica uma filtragem que, em circunstância desrespeitosa, pode até mesmo levar à exclusão de times da liga. (J9) reconhece que a tática faz parte de um contrato: "[...] a gente não pode falar de uma maneira agressiva a outro colega. Na verdade, é um contrato de time quando vai participar da Ligay. Então existem umas regras, no qual a gente não pode ofender, não pode umas coisas..." (J9). 
Observa-se a tentativa de coibir agressões e desrespeito no futebol gay, em comparação ao futebol convencional, considerando-se que nem todos os clubes terão os mesmos níveis de conscientização, como fora reconhecido por (J12). Nesse sentido, é possível salientar que nem mesmo o futebol gay está a salvo do preconceito das demais instituições e, por conseguinte, do preconceito da sociedade. Mesmo outras regras são dispensadas, como atitudes mais tempestivas ante as tentativas de participação de heterossexuais nos clubes, o que caracterizaria a subversão da afirmação que se sustenta e conduziria à ideia de que "todos são iguais", narrativa que certamente prejudicaria a visibilidade e a afirmação do futebol gay.

Uma vez um amigo meu virou para mim e falou assim: "É, mas como é que é um futebol inclusivo, se só aceita o gay?" Concordo, mas, a princípio, nós precisamos mostrar que o gay tem espaço no futebol [...] Mas eu acredito que daqui a uns dez anos isso vai acabar. E o gay assumido vai jogar com o hétero, o hétero vai estar jogando aqui com a gente e não vai ter mais essa: "Ah, o time é gay". É um time de futebol que tem gays e tem hétero jogando e todos se respeitando (J4).

O enunciado de (J4) destaca a questão da inclusão e como a resistência à participação de um jogador heterossexual nos times de futebol gay pode equivaler à não aceitação de gays em times héteros. (J4) atesta otimismo em relação à inclusão plena do homossexual no esporte, a qual, apesar de não ser significativa na contemporaneidade, pode, em curto espaço temporal, atingir maiores níveis. Por caracterizar a atual situação dos clubes gays como algo passageiro, o interlocutor compreende que a organização em times específicos para gays é estratégia momentânea para lidar com o preconceito arraigado na sociedade. Todavia se esquece de que a estigmatização do homossexual, não somente no esporte, faz parte de uma pedagogia e está inserida em um dispositivo histórico, que interdita determinados personagens, garantindo a imutabilidade do esquema (FOUCAULT, 1988; LOURO, 2003). Já (J19) é mais enfático na sua asserção, ensejando alta resistência quanto à inserção de outros sujeitos não gays: "Esse é o nosso local de fala, o nosso ponto de resistência. As meninas, elas já têm muito futebol por aí. Os héteros? Poxa! O que não falta. Olha aqui ao redor! O que mais tem é a 'pelada hétero'. Então ela é nossa, sabe? Pode vir, jogar, mas, assim, você não faz parte do grupo, você é só um convidado que a gente gosta" (J20).

Nesse aspecto, heterossexuais, quando recriminam estas associações desportivas alegando separatismo, portam um discurso de que o esporte não deveria ser nem homossexual nem heterossexual, esquecendo-se de "[...] que ele é profundamente heterossexual e que um gay que se declarasse como tal teria muita dificuldade de continuar a ser admitido numa equipe" (ERIBON, 2008, p. 145). Depreende-se desta classe de enunciados que, embora a linguagem se traduza em uma das principais estratégias de resistência, ela não tem deixado de ser pautada também pela imposição de regras tanto endogenamente como de maneira exógena, de modo a frisar coerência em relação à narrativa que o futebol gay sustenta.

\section{Silenciamentos e invisibilidades}

Segundo Foucault (1988), a repressão não se dá somente pela coerção. Antes ela se vale de um pensamento de injunção ao silêncio e afirmação de inexistência, em que "[...] se for mesmo preciso dar lugar às sexualidades ilegítimas, que vão incomodar noutro lugar: que incomodem lá onde possam ser reinscritas, senão nos circuitos de produção, pelo menos nos de lucro" (FOUCAULT, 1988, p. 9).

(J20) acredita que, nas relações com times de futebol "hétero", não há margem para preconceito, embora apresente isso de maneira controversa:

Tem clube que já fica meio assim: "a gente não pode perder para os gays". E quando eles começam a perder, eles começam a fazer muita falta, porque eu acho que eles podem se sentir inferiorizados. [...] Tem time que não está nem aí. Ele não está indo jogar bola contra um time gay ou contra um time hétero. Ele está indo jogar bola contra um time! [...] E outros times falam: "Ah, é o time dos gays, não vamos perder essa não, se não a gente vai ser o time que perdeu para o time dos gays" (J20).

O que se enuncia é que é preciso, mesmo neste contexto, provar alta performance esportiva. Ou seja, pode ser gay, mas é preciso também "jogar bem". Da fala de (J20), é possível destacar duas atitudes provenientes dos times convencionais em relação aos times de futebol gay. A primeira é uma relação centrada no jogo, em que não importaria a sexualidade dos oponentes. A segunda atitude contradiz a primeira, quando comunica que jogar contra um time gay e sofrer uma derrota é o que denota um time fraco, uma vez que é vigente a expectativa de que o gay não saberia jogar bem futebol (ANDERSON, 2005). Há uma resistência por parte de outros times "héteros" quando se sabe que o confronto se dará com um time gay. 
Nesse aspecto, regula-se a própria homossexualidade no esporte gay. A tolerância ao homossexual é reificada por agentes que, embora o aceitem, fazem-no em conformidade com a masculinidade hegemônica (ANDERSON, 2002). Rememora-se que o discurso gay-friendly tem como característica, justamente, valorizar tão somente a capacidade atlética dos sujeitos perante o esporte. Embora proliferem discursos de aceitação em favor dos gays, uma parte hegemônica ainda possui dificuldade em lidar com a informação (PEREIRA, ALFAIA, SOUZA et al., 2014).

Observou-se também que alguns times gays têm operado quase na invisibilidade. Apesar de os times representarem autêntica resistência no futebol gay, alguns sequer são vistos como times gays. (J18) admite que o time joga bola bem, mas ainda tem "dificuldades para se posicionar como um time gay". Dentre outros times, que ainda não comunicam a própria identidade de time gay, o que persiste é o enfrentamento à ordem discursiva do silêncio. Assim, para apreendê-lo enquanto time gay, seria necessário ou perguntar ou inferir a partir das performances pouco convencionais, e desalinhadas à performatividade, demandada pela sociedade (BUTLER, 2003), sobre quem seria ou não gay, e, por extensão, entender o time como um reduto gay (ALMEIDA e SOARES, 2012; BANDEIRA e SEFFNER, 2013).

Assim, entende-se que o preconceito ainda é um entrave para aqueles que participam de clubes gays. Os enunciados sugerem que, apesar de ser importante a visibilidade, a própria marca da orientação sexual gay pode não vir à tona no quadro das interações dos times de futebol gay com o seu entorno. Para Foucault (1988, p. 95), “[...] é preciso admitir um jogo complexo e instável em que o discurso pode ser, ao mesmo tempo, instrumento e efeito de poder [...] ponto de resistência e ponto de partida de uma estratégia oposta".

Como Foucault (1988) também expunha, o discurso tem como parte integrante os silêncios como estratégia. Nessa dinâmica peculiar de resistência, ao passo que o discurso heteronormativo apodera-se até mesmo da própria causa que os clubes gays trazem para o esporte; em outra medida, vigora e permanece inquestionado o silenciamento gay dentro das próprias instituições esportivas. (J22) pondera:

[...] a indústria do futebol, ela não tem os olhos tão bons para a homossexualidade. Então eu tenho esperança de que os jogadores profissionais e amadores possam expressar sua sexualidade de forma livre [...], talvez daqui a uns 10 anos, a gente possa ver dois...ver dois, sei lá...se beijando...profissionais, na vida deles, pessoais, e todo mundo estar 'cagando e andando para isso' (J22).

O enunciado expressa novamente otimismo quanto à inclusão gay no futebol, de se tornar natural a ponto de não haver segregacionismos. Outrossim, ao mencionar o futebol como indústria, o enunciado permite recuperar a supremacia da linguagem homofóbica nos esportes, em que muitos atletas de alta performance permanecem no armário para serem bem sucedidos. Pode-se inferir que há consciência da momentaneidade da formação de times gays e das barreiras culturalmente impostas a serem vencidas.

\section{CONSIDERAÇÕES FINAIS}

Conclui-se que os discursos adotados operam em uma lógica dual, na qual a presença de enunciados tensionando a ordem gênero-sexualidade e o regime do armário não impede a persistência de enunciados que atuam reforçando esses dispositivos heteronormativos. Os resultados sugerem que, apesar de se lançar mão de diferentes estratégias discursivas, como o humor, para mitigar a injúria homofóbica, o discurso de que é importante, acima de tudo, saber jogar futebol sugere silenciamento e invisibilização dos clubes gays de futebol. A análise possibilitou compreender que, embora o futebol gay no Brasil diferencie-se em vários elementos do futebol convencional, sobretudo no clamor por inclusão e combate à homofobia, experimenta entraves para posicionar-se como frente autêntica de resistência ante o futebol hegemônico, tendo dificuldade de interferir na própria dinâmica de organização desportiva.

Além disso, mesmo no futebol gay, que propaga resistência, concomitantemente práticas discursivas têm sido retomadas e subvertidas ou então reiteradas, referenciando no gay um ideário de masculinidade hegemônica no futebol. Argumenta-se que o discurso foi construído baseado em um contradiscurso. Ou seja, as estratégias discursivas utilizadas permitiram criar o futebol gay como sistema de resistências que possam incluir o gay no esporte e diminuir a influência da heteronormatividade. 
Diante do exposto, fazem-se necessários estudos futuros, dedicados à compreensão do futebol gay, capturando também a faceta da conversação em campo, analisando as interações no decurso da própria interação verbal entre os jogadores, torcedores e demais adeptos das práticas esportivas abordadas. Estimula-se o uso da etnografia discursiva como alternativa para apreender a tomada do discurso em ação no próprio locus de ocorrência da atividade.

O presente estudo contribui para o campo dos estudos organizacionais críticos, sublinhando práticas políticas de organizing em contextos institucionais permeados por práticas discursivas que são, concomitantemente, indícios de poder e de agência-resistência. Por fim, o estudo incentiva, no âmbito de estudos organizacionais críticos, análises pautadas na resistência como fenômeno de natureza organizacional, tomando como relevante a faceta discursiva no mundo do futebol.

\section{AGRADECIMENTOS}

O presente trabalho foi realizado com apoio da Coordenação de Aperfeiçoamento de Pessoal de Nível Superior - Brasil (CAPES) Código de Financiamento 001. 


\section{REFERÊNCIAS}

ALMEIDA, M. B.; SOARES, A. O futebol no banco dos réus: caso da homofobia. Movimento, v. 18, n. 1, p. 301-321, 2012.

ANDERSON, E. In the game: gay athletes and the cult of masculinity. New York: State University of New York Press, 2005.

ANDERSON, E. Inclusive masculinity: the changing nature of masculinities. Londres: Routledge, 2009.

ANDERSON, E. Openly gay athletes: contesting hegemonic masculinity in a homophobic environment. Gender \& Society, v. 16, n. 6, p. 860$877,2002$.

BANDEIRA, G. A. Um currículo de masculinidades nos estádios de futebol. Revista Brasileira de Educação, v. 15, n. 44, p. 342-410, 2010

BANDEIRA, G. A.; SEFFNER, F. Futebol, gênero, masculinidade e homofobia: um jogo dentro do jogo. Espaço Plural, v. 14, n. 29, p. 246-270, 2013.

BORRILLO, D. Homofobia: história e crítica de um preconceito. Belo Horizonte: Autêntica, 2010.

BURY, J. Non-performing inclusion: a critique of the English Football Association's Action Plan on homophobia in football. International Review for the Sociology of Sport, v. 50, n. 2, p. 211-226, 2015

BUTLER, J. Excitable Speech: a politics of the performative. New York: Routledge, 1997.

BUTLER, J. Problemas de gênero: feminismo e subversão da identidade. Rio de Janeiro: Civilização Brasileira, 2003.

CAMARGO, W. X. Dilemas insurgentes no esporte: as práticas esportivas dissonantes. Movimento, v. 22, n. 4, p. 1337-1350, 2016.

CAMARGO, W. X. O armário da sexualidade no mundo esportivo. Estudos Feministas, v. 26, n. 1, p. 1-18, 2018.

CAMARGO, W. X.; RIAL, C. S. M. Competições esportivas mundiais LGBT: guetos sexualizados em escala global? Estudos Feministas, v. 19, n. 3, p. $977-1004,2011$

CASHMORE, E.; CLELAND, J. Fans, homophobia and masculinities in association football: evidence of a more inclusive environment. The British Journal of Sociology, v. 63, n. 2, p. 370-387, 2012.

CAUDWELL, J. 'Does your boyfriend know you're here?' The spatiality of homophobia in men's football culture in the UK. Leisure Studies, v. 30, n. 2 , p. 123-138, 2011

CLELAND, J. Sexuality, masculinity and homophobia in association football: an empirical overview of a changing cultural context. International Review for the Sociology of Sport, v. 53, n. 4, p. 411423, 2018

CLELAND, J.; MAGRATH, R.; KIAN, E. The internet as a site of decreasing cultural homophobia in association football: an online response by fans to the coming out of Thomas Hitzlsperger. Men and Masculinities, v. 21, n. 1, p. 91-111, 2018.

CONNELL, R. W. Masculinities. 2a. ed. Berkeley: University of California Press, 2005.

ERIBON, D. Reflexões sobre a questão gay. Rio de Janeiro: Companhia de Freud, 2008.
FOUCAULT, M. A arqueologia do saber. 7. ed. Rio de Janeiro: Forense Universitária, 2008.

FOUCAULT, M. A ordem do discurso. 5. ed. São Paulo: Edições Loyola, 1999.

FOUCAULT, M. História da sexualidade I: a vontade de saber. 13 ed. Rio de Janeiro: Edições Graal, 1988.

FOUCAULT, M. Microfísica do poder. 13. ed. Rio de Janeiro: Edições Graal, 1998.

HEREK, G. M. Beyond "homophobia": thinking about sexual prejudice and stigma in the twenty-first century. Sexuality Research \& Social Policy, v. 1, n. 2, p. 6-24, 2004.

JARVIS, N. The inclusive masculinities of heterosexual men within UK gay sport clubs. International Review for the Sociology of Sport, v. 50, n. 3, p. 283-300, 2015.

JESUS, D. S. V. "Futebol é coisa para mano, mana e mona?" A LiGay nacional de futebol society do Brasil. Periódicus, v. 1, n. 10, p. 343372, 2019.

JONES, L.; MCCARTHY, M. Mapping the landscape of gay men's football. Leisure Studies, v. 29, n. 2, p. 161-173, 2010.

KIAN, M. et al. Homophobic and sexist yet uncontested: examining football fan postings on internet message boards. Journal of Homosexuality, v. 58, n. 5, p. 680-699, 2011.

KIMMEL, M. S. A produção simultânea de masculinidades hegemônicas e subalternas. Horizontes Antropológicos, v. 4, n. 9, p. 103-117, 1998.

LOURO, G. L. Gênero, sexualidade e educação: uma perspectiva pósestruturalista. 6. ed. Petrópolis: Vozes, 2003.

LUISI, M. L. R.; LUISI, T.; GEANA, M. V. Homosexuality and the heartbeat of a locker room: an analysis of quotations in the context of hegemonic and inclusive masculinity theories. Journal of Homosexuality, v. 63, n. 10, p. 1314-1338, 206.

MAGRATH, R. 'To try and gain an advantage for my team': Homophobic and homosexually themed chanting among English football fans. Sociology, v. 52, n. 4, p. 709-726, 2018

MISKOLCI, R. O desejo da nação: masculinidade e branquitude no Brasil de fins do XIX. São Paulo: Annablume, 2013

MISKOLCI, R. Teoria queer: um aprendizado pelas diferenças. Belo Horizonte: Autêntica, 2012

OLIVEN, R. G.; DAMO, A. S. Fútbol y cultura. Buenos Aires: Editorial Norma, 2001

PEREIRA, A. S. et al. Preconceito contra homossexuais no contexto do futebol. Psicologia \& Sociedade, v. 26, n. 3, p. 737-745, 2014.

PIEDRA, J. Gays y lesbianas en el deporte: discurso de jóvenes universitarios españoles en torno a su aceptación. Movimento, v. 21, n. 4, p. 1067-1081, 2015.

SEDGWICK, E. K. Between men: english literature and male homosocial desire. New York: Columbia University Press, 1985. 
SEDGWICK, E. K. Epistemology of closet. In ABELOVE, H.; BARALE, M. A.; HALPERIN, D. M. (Eds.). The Lesbian and Gay Studies Reader. New York: Routledge, 1993. p. 45-61.

SILVA JÚNIOR, J. A. Pedagogia do armário: identidade, pertencimento e apropriação do futebol por torcedores homossexuais. 2018. $160 f$. Tese (Doutorado em Estudos do Lazer) - Universidade Federal de Minas Gerais, Escola de Educação Física, Fisioterapia e Terapia Ocupacional, 2018.

SOUZA, E. M. A teoria queer e os estudos organizacionais: revisando conceitos sobre identidade. Revista de Administração Contemporânea, v. 21, n. 3, p. 308-326, 2017.

SOUZA, E. M.; COSTA, A. S. M.; LOPES, B. C. Ressocialização, trabalho e resistência: mulheres encarceradas e a produção do sujeito delinquente. Cadernos EBAPE.BR, Rio de Janeiro, v. 17, n. 2, p. $362-$ 374, 2019.

SOUZA, E. M.; COSTA, A. S. M.; PEREIRA, S. J. N. A organização (in)corporada: ontologia organizacional, poder e corpo em evidência. Cadernos EBAPE.BR, Rio de Janeiro, v. 13, n. 4, p. 727-742, 2015.

SPARGO, T. Foucault e a teoria queer: seguido de Ágape e êxtase: orientações pós-seculares. Belo Horizonte: Autêntica, 2017.

STASI, M.; EVANS, A. Glitter (foot)ball tactics: negotiating mainstream gender equality in Iceland. Men and Masculinities, v. 16, n. 5, p. 560-578, 2013.

WILLIS, T. Kicking down barriers: gay footballers, challenging stereotypes and changing attitudes in amateur league play. Soccer \& Society, v. 16, n. 2-3, p. 377-392, 2015.

Gustavo Henrique Carvalho de Castro

ORCID: https://orcid.org/0000-0003-3920-6404

Doutorando em Administração pelo Programa de Pós-Graduação em Administração da Universidade de Brasília (UNB), Brasília - DF, Brasil.

E-mail: gustavo.hc.castro@gmail.com 